\title{
Chair Side Diagnostic Test Kits in Periodontics
}

Tejaswi Chepuri ${ }^{1}$, J agadish Reddy Gooty², Satyanarayana Durvasala ${ }^{3}$, Rajababu Palaparthi ${ }^{4}$

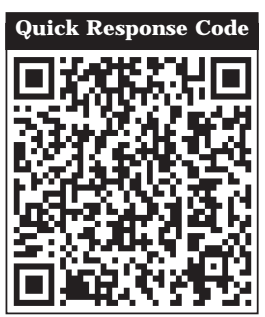

doi : 10.5866/2015.7.10041

${ }^{1}$ Post Graduate

${ }^{2}$ Reader

${ }^{3}$ Professor

${ }^{4}$ Prof \& HOD

Department of Periodontics

Kamineni Institute of Dental Sciences

Sreepuram, Narketpally-508254

\section{Article Info:}

Received: J anuary 9, 2015

Review Completed: February 10, 2015

Accepted: March 11, 2015

Available Online: April, 2015 (www.nacd.in)

(c) NAD, 2015 - All rights reserved

\section{Email for correspondence:}

drjagadishreddy@gmail.com

\section{ABSTRACT:}

As periodontitis is increasing in prevalence, there is a need for development of new diagnostic tests that detect the presence of active disease, predict future disease progression, and evaluate the response to periodontal therapy, thereby improving the clinical management of periodontal patients. For this purpose both GCF and saliva serves to be reliable and non invasive medium toanalyze biomarkers chair side. This articlehighlights various chair side diagnostic kits that facilitate diagnosis and improve prognosis.

Key words: Periodontal disease, Diagnosis, Saliva, Gingival crevicular fluid

\section{INTRODUCTION}

Periodontal diseases are prevalent human diseases defined by the signs and symptoms of gingival inflammation and/or periodontal tissue destruction. These diseases are conventionally diagnosed by clinical evaluation of the signs of inflammation in the gingiva without periodontal tissue destruction (gingivitis) or by the presence of both inflammation and tissue destruction (periodontitis). A clinical diagnosis of periodontitis is made by measuring the loss of connective tissue attachment to the root surface (clinical attachment loss) and loss of alveolar bone (radiographic bone loss). ${ }^{1}$

This information provides evidence of past periodontal destruction, as well as its extent and severity but does not provide any information on the cause of the condition, patient's susceptibility to disease, whether the disease is progressing, whether it is in remission or whether the response to therapy is positive or negative. As periodontal disease is multifactorial in origin consideration should be given to include microbiologic, immunologic, systemic, genetic and behavioral factors, in addition to the traditional clinical and radiographic parameters, when assessing patient status. ${ }^{1}$

The philosophy behind the emergence of various diagnostic tests is that the earlier the active disease is diagnosed, the less invasive, the less time consuming and therefore the less costly the required treatment and the better long-term prognosis for 
patients with destructive disease. ${ }^{2} \mathrm{~F}$ or periodontal diagnosis, the ideal diagnostic test should be:

1. Quantitative.

2. Highly sensitive method capable of analyzing a single periodontal site in health as well as disease.

3. Reproducible.

4. Highly specific.

5. Simple to perform.

6. A rapid, one or two stage procedure.

7. Non-invasive.

8. Versatile in terms of sample handling, storage and transport.

9. Amendable to chair side use.

10. E conomical.

11. Dependent upon simple and robust instrumentation. $^{3}$

A given detection method may mistakenly identify non-target microorganisms and may not detect all strains of the target bacterial species due to strain to strain variability. Sensitivity denotes the percentage of positive test results of a detection method employed to identify different strains of the target microbial species and Specificity denotes the percentage of negative results when the detection method is applied to a variety of non-target bacterial species. The ideal detection method displays sensitivity and specificity of $100 \%{ }^{4}$

Various technical difficulties in conventional procedures from sample taking to dispersion, cultivation, characterization and identification of isolates and problems associated with adequate analysis of microbiologic data makes conventional diagnostic procedures time taking and cumbersome. ${ }^{1}$ In this context chair side periodontal diagnostic kits provide immediate reports.

Advantages of chair side diagnostic kits:

- Simple to use

- Can be read after relatively short periods

- Can be shown to patient and relate to the tooth site affected.

They are categorized as: Microbiologic kits, Biochemical kits, Genetic kits (Table 1).

\section{Microbiologic test kits EVALUSITE}

The Evalusite Test (E astman Kodak Company) is a polyclonal antibody based sandwich enzyme immunoassay. It allows for the visual detection and differentiation of antigens from $A$. actinomycetemcomitans, $P$. gingival is and $P$. intermedia in subgingival paper point samples. The
Evalusite test is well-suited for the simultaneous testing of multiple samples since minimal sample dilution occurs when multiple paper points are placed in a single sample tube. The likelihood of detecting bacterial colonization with the Evalusite test was shown to be greater in deep pockets as compared to shallow pockets. ${ }^{5}$ Various drawbacks of this test are it is multistage test, it has a subjective cal orimetric end point, there is no permanent record of the result and gives the assumption that the three organism are causing the disease. ${ }^{6}$ Evalusite had a sensitivity of $28 \%$ and a specificity of $98 \%$ for A. actinomycetemcomitans and $52 \%$ sensitivity and a specificity of $98 \%$ for $\mathrm{P}$. gingivalis. ${ }^{4}$

\section{PERIOSCAN}

It is a chair side assay that detects a group of periodontal pathogens B. forsythus, P. gingivalis, T. denticola as well as certain Capnocytophaga species that produce trypsin like enzyme. ${ }^{7}$ It cannot identify the presence of other pathogens that do not produce trypsin like enzyme. The results are qualitative and rely upon the operator's assessment at the calorimetric end point. The specific bacteria that are responsible for enzyme production can't be determined. ${ }^{6}$ Perioscan had a sensitivity of $99 \%$ and a specificity of $55 \%{ }^{7}$

\section{OMNIGENE (DMDX)}

A. actinomycetemcomitans cloned probe and $P$ gingivalis whole genomic probe comprise the basis of the commercial DMDx (Figure 1) detection method. For P. gingivalis, the DNA probe assay can give false negative data. ${ }^{8}$ Steenbergen et al found the DMDx detection method to possess $96 \%$ sensitivity and $86 \%$ specificity for spiked laboratory specimens of $A$. actinomycetemcomitans and $60 \%$ sensitivity and $82 \%$ specificity for laboratory specimens of $\mathrm{P}$.gingivalis. ${ }^{8}$ However, in clinical specimens, the detection of $A$. actinomycetemcomitans revealed sensitivity as low as $21 \%$ and a specificity of $83 \%$. For $\mathrm{P}$ gingivalis, the sensitivity was $71 \%$ and the specificity $53 \%$.

\section{IAI PADO TEST 4.5}

With the PADO RNA probe test kit, four periodontal pathogens can be detected: A. actinomycetemcomitans, $P$. gingivalis, $T$. forsythia and $T$. denticola. This test uses oligonucleotide probes complementary to conserved fragments of the 16S rRN A gene that encodes the rRNA, which forms a subunit of the bacterial ribosome. The detection threshold of this test is 103 for A. actinomycetemcomitans and 104 for P. gingivalis, $T$. forsythia and $T$. denticola. The detection frequencies found indicated a low sensitivity of the PadoTest 4.5 method compared to the checkerboard 
method. The PadoTest 4.5 seems to underestimate the number of positive sites/individuals suggested by a high number of false negatives. ${ }^{9}$

\section{My PerioPath}

My PerioPath uses a saliva sample to identify the type and concentration of the specific bacteria that cause periodontal diseases. This test requires the shipping of saliva samples to a laboratory for results.

\section{DNA probes}

\section{Merits}

- DNA probes are very specific and are used to determine phenotypic markers.

- It has great specificity and sensitivity. They are not affected by transport conditions.

- They do not require anaerobic conditions to be maintained.

- They can be done in dead bacteria and they do not depend on bacterial viability. ${ }^{6}$

\section{Demerits}

- They are very expensive.

- The minimal detection limits are 103 to 105 cells of particular species.

- The chair side diagnosis is not possible.

- The cross reactivity by oligonucleotide probes can occur.

- Antibiotic sensitivity is not possible. ${ }^{6}$

\section{Biochemical kits}

\section{Perio-Check (Ac Tech)}

It is the most rapid chair side test for neutral proteases like collagenases in GCF. The levels of these enzymes in GCF have been noted to increase with the development of gingivitis as well as sites of established periodontitis. Not specific for PMNL collagenase. I nterproximal sites cannot be sampled due to the risk of saliva contamination. ${ }^{7}$ Periocheck had a sensitivity of $88 \%$ and a specificity of $61 \%{ }^{7}$

\section{Prognos-Stik (Dentsply)}

This system detects the presence of serine proteinase elastase in GCF sample. ${ }^{10}$

\section{Periogard TM}

PerioGard is based on the measurement of levels of enzyme aspartate ami notransferase (AST) in GCF sample. The test is designed to be positive at $>800$ $\mu \mathrm{IU}$ of AST activity and negative at values less than $800 \mu \mathrm{IU}$. It cannot discriminate between sites with severe inflammation but with no attachment loss from sites with attachment loss. ${ }^{11}$

\section{PocketWatch $^{\text {TM }}$}

The PocketWatch ${ }^{\mathrm{TM}}$ method analyzes AST at the chair side. It is possible to distinguish between active and inactivesites with PocketWatch ${ }^{\mathrm{TM}}$. AST activity determined by PocketWatch ${ }^{\mathrm{TM}}$ provides not only an index of cell death but of the extent of the destructive pockets. ${ }^{12}$

\section{Perio2000}

Perio 2000 system (Figure 2 ) is designed so that it combines the features of a periodontal probe with the detection of volatile sulphur compounds in the periodontal pocket. ${ }^{13}$

\section{Dip Stick Test}

The MMP-8 test stick is based on the immunochromatography principle that uses two monoclonal antibodies specific for different epitopes of MMP-8. The test stick results can be detected in 5 mins. The antibody detects both neutrophils and non-PMN-type MMP-8 isoforms. ${ }^{14}$

\section{TOPAS (Toxicity Prescreening Assay)}

TOPAS (Figure 3 ) detects the indirect presence of bacteria by two markers of gingival infection: bacterial toxins and bacterial proteins. This test can be associated with the severity of inflammation and with the evolution of destructive process making the difference between an active and an inactive periodontal disease. ${ }^{15}$

\section{Integrated Microfluidic Platform for Oral Diagnostics (IMPOD)}

A clinical point-of care diagnostic test that enables rapid quantification of an oral disease biomarker in human saliva by using a monolithic disposable cartridge designed to operate in a compact analytical instrument. This microfluidic method facilitates hands-free saliva analysis by integrating sample pretreatment (filtering, enrichment, mixing) with electrophoretic immunoassays to quickly measure analyte concentrations in minimally pretreated saliva samples. Rapidly (<10 min) measures MMP-8 in saliva from healthy and periodontally diseased subjects. It requires low sample volume $(10 \mu \mathrm{L}){ }^{16}$

\section{Oral Fluid Nano Sensor Test (OFNASET)}

OFNASET (Figure 4) is a micro electromechanical system based electrochemical detection platform that is capable of real-time, ultrasensitive, ultraspecific multiplex detection of salivary protein and RNA biomarkers. OFNASET is used for the point of care multiplex detection of salivary biomarkers for oral cancer. It analyzes saliva for the presence of four salivary mRNA biomarkers (SAT, ODZ, IL-8, and IL-1 $\beta$ ) and two 


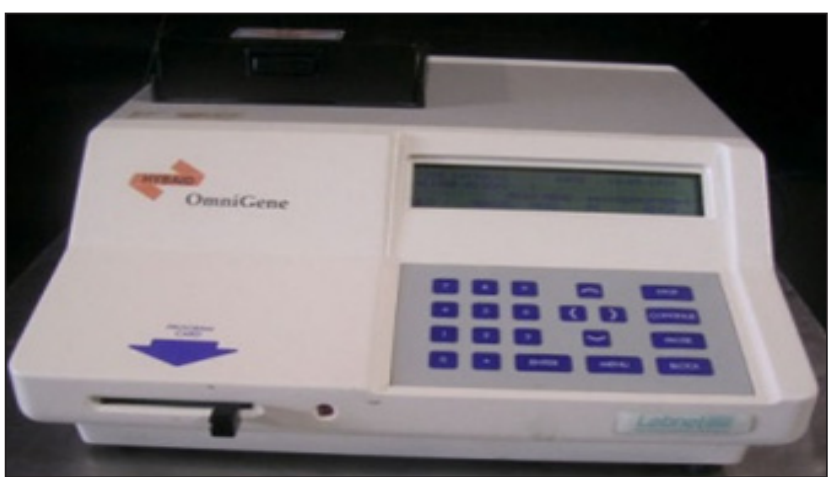

Figure 1: Omnigene

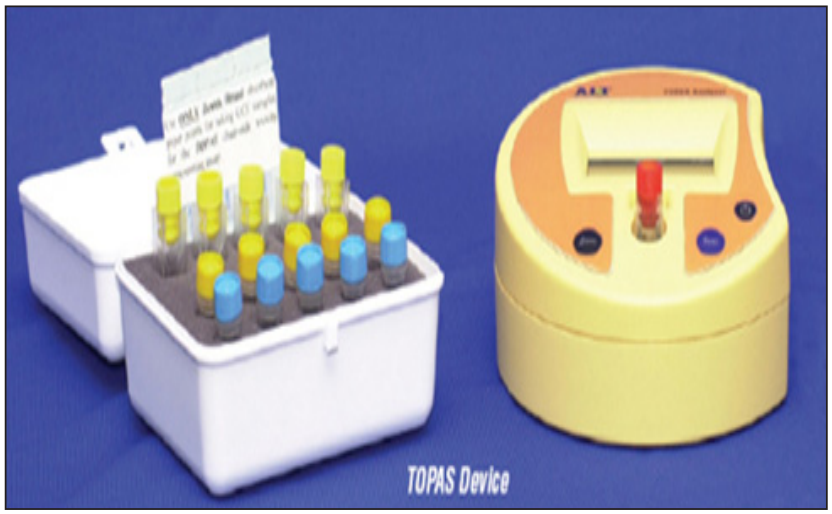

Figure 3: TOPAS device

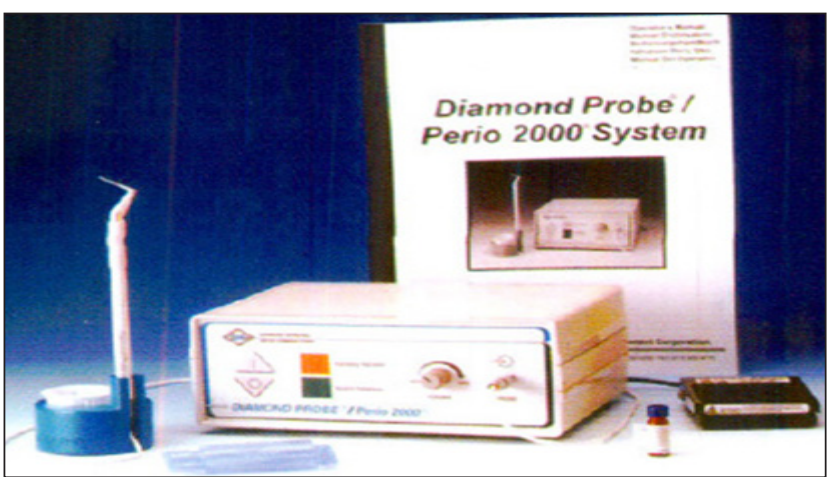

Figure 2: Perio 2000

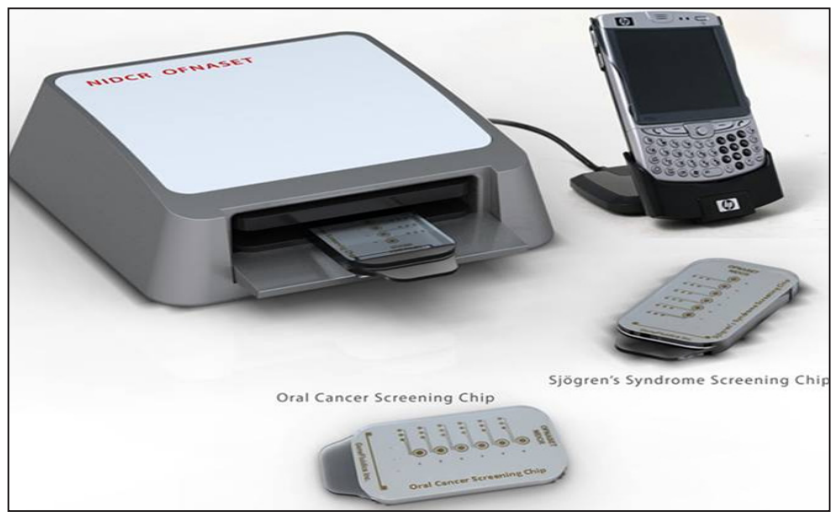

Figure 4: OFNASET

Table 1: Chair side test kits

\begin{tabular}{|c|c|c|}
\hline Classification & Trade name & Evaluation \\
\hline \multirow[t]{4}{*}{ Microbiological } & $\begin{array}{l}\text { Evalusite } \\
\text { (Eastman Kodak Company) }\end{array}$ & $\begin{array}{l}\text { Visual detection and differentiation of antigens from } \\
\text { A. actinomycetemcomitans, P. gingivalis and P. intermedia. }\end{array}$ \\
\hline & Perioscan & $\begin{array}{l}\text { Detects periodontal pathogens B. forsythus, P. gingivalis, } \\
\text { T. denticola as well as certain Capnocytophaga species that } \\
\text { produce trypsin like enzyme. }\end{array}$ \\
\hline & Omnigene(DMDx) & $\begin{array}{l}\text { DNA probe for detection of A. actinomycetemcomitans, } \\
\text { P. gingivalis. }\end{array}$ \\
\hline & IAI pado test & $\begin{array}{l}\text { Oligonucleotide probe for detection of } \\
\text { A. actinomycetemcomitans, P. gingivalis, T. forsythia and } \\
\text { T. denticola. }\end{array}$ \\
\hline \multirow[t]{10}{*}{ Biochemical } & Periocheck & Detects neutral proteases like collagenases in GCF \\
\hline & Prognostik & Detects serine proteinase elastase in GCF \\
\hline & Pocket watch & Detects AST in GCF \\
\hline & Periogard & Detects AST in GCF \\
\hline & Perio 2000 & Detects VSC \\
\hline & TOPAS & Detects bacterial toxins and proteins \\
\hline & Dip stick & Detects MMP-8 in GCF \\
\hline & IMPOD & Saliva based detection of MMP-8 \\
\hline & OFNASET & Saliva based detection of IL-1,IL-8 \\
\hline & $\overline{\mathrm{ETC}}$ & Detects CRP \\
\hline \multirow[t]{2}{*}{ Genetic } & PST & Detects IL-1 polymorphism \\
\hline & MyPeriol D & Saliva based detection of genetic susceptibility \\
\hline
\end{tabular}


salivary proteomic biomarkers (thioredoxin and IL8). Simultaneous detection of multiple salivary proteins and nucleic acids is possible. ${ }^{17}$

\section{Electronic Taste Chips (ETC)}

They are chemically sensitized bead microreactors within the lab-on- a-chip system and were applied for measurement of CRP and other biomarkers of inflammation in saliva. The ETC methodology was compared with the standard laboratory technology (ELISA) for measuring CRP in saliva and displayed a 20-fold lower limit of detection than the ELISA. With this technique it was possible to quantitate the difference in CRP levels between heal thy individuals and patients with periodontal diseases and can simultaneously monitor several biomarkers. ${ }^{18}$

\section{Genetic test kits}

The periodontitis susceptibility trait test (PST) is the genetic susceptibility test for severe periodontitis that is commercially available. It evaluates the simultaneous occurrence of allele 2 at the IL-1A +4845 and 1B +3954 loci. ${ }^{19}$

\section{MyPeriol D}

MyPeriol D test uses saliva to determine a patient's genetic susceptibility to periodontal diseases and which patients are at higher risk of more serious periodontal infections. This test require the shipping of saliva samples to a laboratory for results. ${ }^{20}$

\section{CONCLUSION}

Chair side diagnostic kits offer rapid, reproducible mode of diagnosis and the results can be used for patient motivation as well. They are useful especially in making out the active site and monitoring patients post treatment for evaluating the response to therapy and disease recurrence. Integrating new salivary diagnostic methods to clinical practice is important to aid dental professionals in making essential health-related decisions for patients.

\section{References}

1. Mariano Sanz, Michael G Newman, Marc Quirynen. Advanced diagnostic techniques in Carranza FA, Newman MG, Takei HH-Text book of Clinical Periodontology. Philadel phia: Saunders 1996;579-601:10 th edition.

2. Kinane DF. Regulators of tissue destruction and homeostasis as diagnostic aids in periodontology. Periodontol 2000; 24:215-25.

3. Chapple IL. Periodontal diagnosis and treatment-where does the future lie? Periodontol 2009; 51:9-24.

4. Chen C and Slots J. Microbiological tests for Actinobacillus Actinomycetemcomitans and Porphyrornonas gingivalis. Periodontol 1999; 20:53-64.
5. Boyer BP, Ryerson CC, Reynolds HS, Zamhon JJ, Genco RJ, Snyder B. Colonization by Actinohacillus actinomycetemcomitans, Porphyromonas gingivalis and Prevotella intermedia in adult periodontitis patients as detected by the antihody-based Evalusite Test. J Clin Periodontol 1996; 23:477-484.

6. Malathi K, Sharmila K, Sable D, Ahamed S. Microbial Diagnosis in Periodontics: Merits and Demerits: A Review. J Dent Med Sci 2014; 13(2):104-107.

7. Hemmings KW, Griffiths GS, Bulman J S. Detection of neutral protease (Periocheck) and BANA hydrolase (Perioscan) compared with traditional clinical methods of diagnosis and monitoring of chronic inflammatory periodontal disease. J Clin Periodontol 1997; 24:110-114.

8. van Steenbergen TJ M, Timmerman MF, Mikx FHM, de Quincey G, van der Weijden GA. van der Velden U, de Graaff $J$. Discrepancy between culture and DNA probe analysis for the detection of periodontal bacteria. J Clin Periodontol 1996; 23:955-959.

9. Leonhardt A, Carlen A, Dahlen G. Detection of Periodontal Markers in Chronic Periodontitis. Open Dent J 2011; 5: 110-115.

10. Eley BM, Cox SW. Advances in periodontal diagnosis. Brit Dent J 1998; 220-223,323-328,373-376,427-430,489-492.

11. Persson GR, Alves MEAF, Chambers DA, Clark WB, Cohen R. Crawford J M, DeRouen TA, Magnusson I, Schindler T, Page RC. A multicetiter clinieal trial of PerioGard ${ }^{\mathrm{TM}}$ in distinguishing between diseased and healthy periodontal sites. Study design, methodology and therapeutic outcome. J Clin Periodontol 1995; 22:794-803.

12. Shimada K, Mizuno T, Ohshio K, Kamaga M, Murai S, I to $\mathrm{K}$. Analysis of aspartate aminotransferase in gingival crevicular fluid assessed by using PocketWatch ${ }^{\mathrm{TM}}$ : a Iongitudinal study with initial therapy. J Clin Periodontol 2000; 27:819-223.

13. Gupta M, Nirola A, Bhardwaj SJ. Advances in clinical diagnosis in Periodontics.Indian J ournal of Dental Sciences 2012; 4(4):114-118.

14. Mantyla P, Stenman M, Kinane DF, Tikanoja S, Luoto H, Salo T, Sorsa T. Gingival crevicular fluid collagenase-2 (MMP-8) test stick for chair-side monitoring of periodontitis. J Periodontal Res 2003; 38(4):436-439.

15. Cristina Gabriela Pucau, Anca Dumitriu, Horia Traian Dumitriu. Biochemical and enzymatic diagnosis aids in periodontal disease. OHDMBSC 2005; 4:19-25.

16. Herr AE, Hatch AV, GiannobileWV. Integrated microfluidic platform for oral diagnostics. Ann N Y Acad Sci 2007; 1098: 362-374.

17. Priyanka $\mathrm{N}$ et al. Recent approaches in saliva as a credible periodontal diagnostic and prognostic marker. Arch Oral Sci Res 2012; 2(1):40-46.

18. Christodoulides N, Mohanty S, Miller CS. Application of microchip assay system for the measurement of C-reactive protein in human saliva. Lab Chip 2005; 5:261-269.

19. Greenstein G, Hart T. A critical assessment of IL-1 genotyping when used in a genetic susceptibility test for severe chronic periodontitis. J Periodontol 2002; 73(2):231247.

20. Tran J and Malamud D. Salivary diagnostics. Dimensions of Dental Hygiene 2011; 9(2):56-59. 